\title{
GEOCHEMICAL PROCESSES OCCURRING IN THE WATERS AT THE AMAZON RIVER/ OCEAN BOUNDARY
}

By David J. DeMaster, Brent A. McKee, Willard S. Moore, David M. Nelson, William J. Showers and Walker O. Smith, Jr.

G TEOCHEMICAL REACTIONS occurring in estuarine waters can significantly affect the riverine flux of nutrients, minor elements, and trace elements to the ocean. Biological uptake, adsorption/desorption reactions, coagulation, as well as precipitation of iron hydroxides and high-molecular-weight organic acids, all can affect the chemical flux to the marine environment (e.g., Boyle et al., 1977; Sholkovitz et al., 1978; DeMaster et al., 1986). Many studies investigating these chemical reactions have been conducted in the estuaries of small rivers (discharge $<10^{14} 1 \mathrm{y}^{-1}$ ) because of simplicity in modeling the hydrographic regime or because of logistical reasons. Geochemical studies in these small estuarine systems have provided valuable insight to the chemical reactions that occur during the mixing of riverine and oceanic waters. However, much of the chemical flux from rivers enters the ocean via large dispersal systems. For example, the Amazon River alone supplies $17 \%$ of all the dissolved silica reaching the marine environment via rivers (Livingstone, 1963). Estuarine processes occurring in the more frequently studied small dispersal systems are extrapolated to those occurring in the large dispersal systems, but the validity of this extrapolation is unclear.

Suspended-sediment concentration is one of the important factors that differs between small and large dispersal systems. Small river systems commonly have suspended-sediment concentrations in surface waters on the order of tens of $\mathrm{mg}$ $\mathrm{I}^{-1}$, whereas large rivers (i.e., the Amazon River or Yangtze River) have suspended sediment concentrations on the order of hundreds of $\mathrm{mg} \mathrm{l}^{-1}$.

D.J. DeMaster, W.J. Showers, Department of Marine, Earth and Atmospheric Sciences, North Carolina State University, Raleigh, NC 27695 USA. B.A. McKee, Louisiana Universities Marine Consortium, Chauvin, LA 70344 USA. W.S. Moore. Department of Geological Sciences, University of South Carolina, Columbia, SC 29208 USA. D.M. Nelson, College of Oceanography, Oregon State University, Corvallis, OR 97331 USA. W.O. Smith, Jr., Program in Ecology, University of Tennessee, Knoxville, TN 37996 USA.
This project examines the many chemical processes occurring near the mouth of the Amazon River that are affected by the enormous discharge of sediment particles. The specific topics studied in this portion of AmasSeds (A Multidisciplinary Amazon Shelf SEDiment Study) include the evaluation of: 1) the effects of suspended sediment concentrations on the biological uptake and regeneration of nutrients and carbon; 2) scavenging of particle-reactive elements (e.g., Th and $\mathrm{Pb}$ ) from the water column; and 3) mixing and transport of Amazon shelf waters by measuring radium isotopes released from suspended sediments and the oxygen isotopic signature of different water masses. Of the four AmasSeds cruises, three have been completed (I: falling river discharge in August 1989; II: rising discharge in March 1990; and III: high discharge in May 1990). Initial results from geochemical studies of the waters at the Amazon River/ocean boundary are presented below.

\section{Biological Uptake and Regeneration of Nutrients and Carbon}

Previous studies on the Amazon shelf have shown the importance of suspended sediment concentration on limiting light penetration and thereby nutrient uptake by phytoplankton (Milliman and Boyle, 1975; Edmond et al., 1981; DeMaster et al., 1983, 1986). In these studies, however, rates of primary production and rates of nutrient uptake were never measured as a function of suspended-solid concentration (only inferred from standing crop measurements). As part of the hydrographic legs of AmasSeds cruises, rates of primary production, dissolved-silica uptake, and particulate-silica regeneration, in addition to the distributions of chlorophyll- $a$ and nutrients (silica, phosphate, nitrate, nitrite, ammonia, and urea), were measured in the water column. During the three field studies a region of high biological activity was observed in approximately the same geographical area (Fig. 1). The region closest to the coast (which had the highest turbidities) exhibited extremely low chlorophyll-
Estuarine processes

occurring in . . . small dispersal systems are extrapolated to those occurring in the large dispersal systems, but the validity of this extrapolation is unclear. 


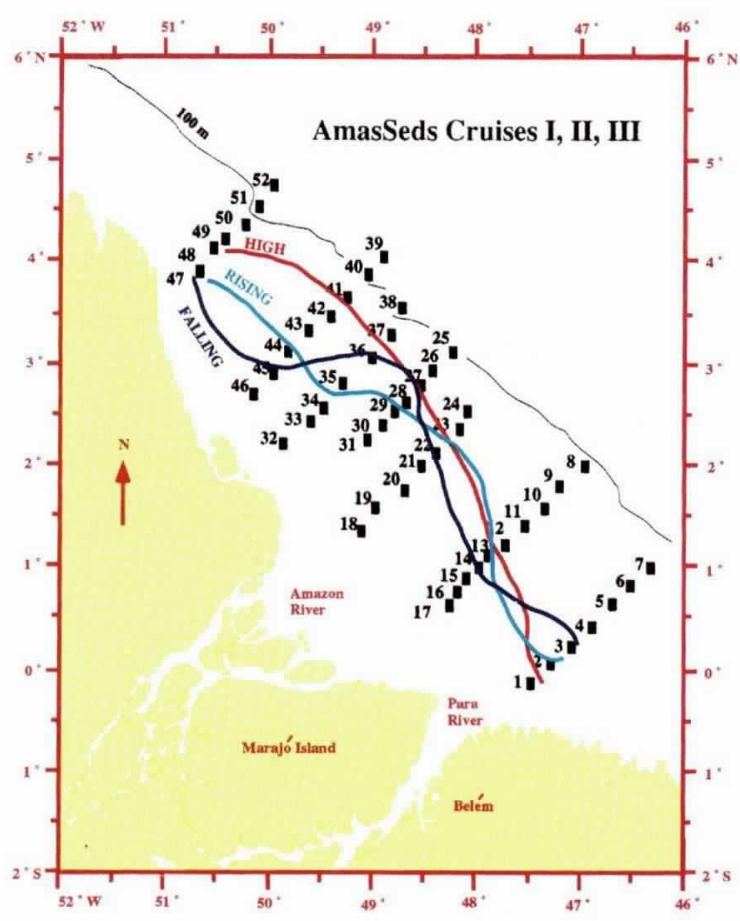

Fig. 1: The location of the boundary between the high-turbidity and high-chlorophyll-a zones during Amasseds cruises I, II, and III (falling, rising, and high river discharge, respectively). The front remains relatively stationary near the river mouth but is somewhat variable in the northwestern portion of the study area. The cruises were conducted in August 1989 (I), March 1990 (II), and May (III) 1990; station numbers are shown.

... phytoplankton

productivity was limited

nearshore due to

inadequate irradiance

resulting from high

concentrations of

suspended, inorganic

particles. with the scenario that phytoplankton productivity was limited nearshore due to inadequate irradiance resulting from high concentrations of suspended, inorganic particles. In the offshore region far from the influence of the river, reduced phytoplankton growth occurred probably as a result of deficient nutrient supply. In the region between these two zones, where both nutrients and irradiance were elevated, rapid growth and high biomass occurred. A CZCS image of the Amazon shelf taken in June 1983 shows a similar highchlorophyll band just seaward of the high turbidity plume (Curtin and Legeckis, 1986).

Rate measurements for silica uptake and silica regeneration were made during the three AmasSeds cruises using the silicon stable isotope technique described by Nelson and Goering (1977). During cruise I, net uptake of silica by phytoplankton appears to be confined to the chlorophyll-rich waters seaward of the main turbidity front, and in these waters biological uptake was very rapid (Fig. 2). Vertical profiles of biogenic silica (Fig. 2a) show that station 45, which exhibited the elevated chlorophyll- $a$ levels, had a considerably higher standing stock of biogenic silica throughout the upper few meters. Rate measurements showed that this station also had much higher rates of biogenic silica production (Fig. 2b) and considerably lower rates of silica regeneration (Fig. 2c). Data from nocturnal incubations at station 54 (not shown) indicate that biogenic silica production continued through the night at rates approximately equal to those measured in daytime, as has been observed in several other systems (e.g., Nelson et al., 1981; Brzezinski and Nelson, 1989). Thus, the daytime rates shown in Figs. $2 b$ and $2 \mathrm{c}$ appear to provide reasonable estimates of temporally integrated daily silica fluxes.

The resulting net balance between silica production and regeneration rates (Fig. 2d) indicates that on a vertically integrated basis little or no net production of biogenic silica is occurring at the high-turbidity sites, but that the lower-turbidity/ higher-chlorophyll station exhibited significant net production. The vertically integrated net rate of biogenic silica production at this station was 41 $\mathrm{mmol} \mathrm{SiO}_{2} \mathrm{~m}^{-2} \mathrm{~d}^{-1}$ which is approximately equal to the mean of all silica production rates reported from highly productive, diatom-dominated coastal upwelling zones (as summarized by Brzezinski and Nelson, 1989).

Nutrient removal on the shelf is consistent with the spatial distribution of primary production, chlorophyll $a$, and silica uptake. The uptake of nutrients seaward of the high turbidity plume is most apparent in the distributions of dissolved silica/salinity and nitrate/salinity ratios, whereas the distributions of phosphate/salinity and ammonia/salinity ratios are complicated by adsorption/desorption reactions and nutrient recycling processes, respectively (Fox et al., 1986). In pre- 
vious studies of the Amazon shelf, ammonia and urea concentrations rarely were measured, which made conclusions regarding inorganic $\mathrm{N}$ dynamics somewhat ambiguous. On all three of the AmasSeds cruises, dissolved nitrate, nitrite, ammonia, and urea were measured. Near the river mouth, the dissolved inorganic nitrogen is dominated by nitrate ( 85 to $100 \%$ of the 9 to $22 \mu \mathrm{mol}$ $\mathrm{kg}^{-1}$ signal), whereas farther offshore, nitrate comprises a smaller portion ( 25 to $60 \%$ ) of the 0 to $2 \mu \mathrm{mol} \mathrm{kg}{ }^{-1}$ signal (with the remainder being primarily ammonia). Profiles of dissolved oxygen, dissolved inorganic carbon (including carbon isotopic analyses), alkalinity, $\mathrm{pH}$, light transmission, and fluorescence, also have been measured at the hydrographic stations to complement the nutrient and productivity measurements.

\section{Scavenging of Particle-Reactive Elements}

Chemical reactions occurring in estuaries (adsorption, desorption, coagulation, precipitation of iron oxides and humic acids) affect the transport pathways of numerous trace metals and determine the ultimate flux of these elements to the open ocean. Measurements of naturally occurring particle-reactive tracers such as ${ }^{234} \mathrm{Th}$ and ${ }^{210} \mathrm{~Pb}$ can be used to examine trace metal residence times in the water column as well as transport pathways. ${ }^{234} \mathrm{Th}$ is produced from the decay of ${ }^{238} \mathrm{U}$ is seawater. ${ }^{210} \mathrm{~Pb}$ reaches the Amazon shelf via in situ decay of its effective parent, ${ }^{226} \mathrm{Ra}$, in seawater and via atmospheric deposition as a result of ${ }^{222} \mathrm{Rn}$ decay. In a previous study (McKee et al., 1986), laboratory measurements were used to develop a model describing the kinetics of particle scavenging on the Amazon shelf for suspended solid concentrations ranging from 1 to $1000 \mathrm{mg} / \mathrm{l}$. Field experiments conducted during the first three cruises of AmasSeds were designed to test this kinetic model. Multiple bulk-water samples were collected from individual field sites and the partitioning between dissolved and particulate radionuclides was monitored over a period of hours to days as chemical equilibrium was approached. Initial results from the field experiments (Fig. 3) appear to corroborate the kinetic model established from the laboratory studies. Recently, Honeyman and Santschi (1989) have described the importance of colloidal processes on trace metal removal from seawater. Based on these insights, ultrafiltration techniques will be employed during the AmasSeds IV cruise to evaluate the importance of colloids for particle scavenging in the Amazon River/ocean mixing zone.

In a related study the seabed inventories of these particle-reactive species are being measured during AmasSeds cruises. DeMaster et al. (1986) showed that most of the ${ }^{210} \mathrm{~Pb}$ (half life $22 \mathrm{y}$ ) deposited in the Amazon subaqueous delta was derived from shoreward advection of open-ocean waters. Some of the seabed ${ }^{210} \mathrm{~Pb}$ data from pre-
BIOGENIC SILICA

$$
\left(\mathrm{mmol} * \mathbf{m}^{-3}\right)
$$

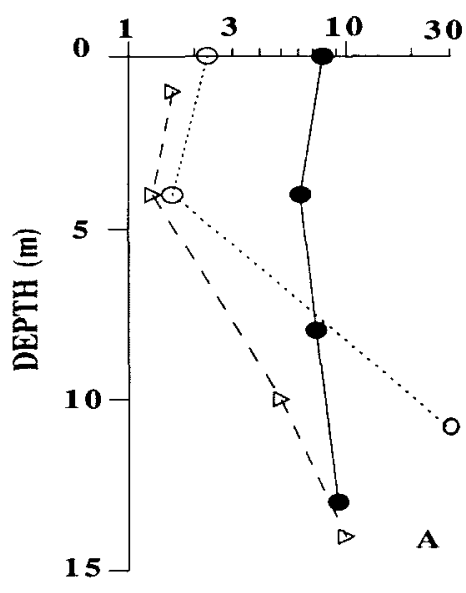

SILICA DISSOLUTION RATE

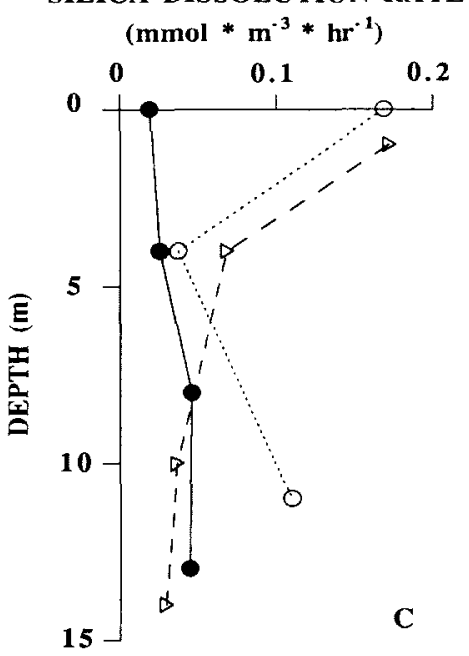

SILICA PRODUCTION RATE $\left(\mathrm{mmol} * \mathbf{m}^{-3} * \mathbf{h r}^{-1}\right)$

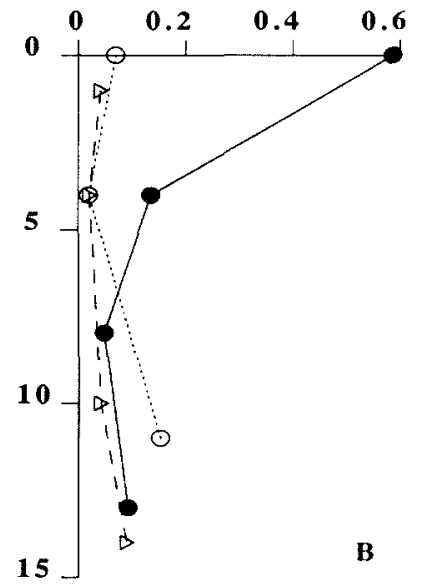

B
Fig. 2: Biogenic silica concentrations (a), production rates (b), dissolution rates (c), and the net balance between silica production and regeneration (d) at three stations occupied during AmasSeds Cruise I (August, 1989). Open symbols depict stations $20(\mathrm{O})$ and $54(\triangle)$, taken in turbid, chlorophyll-poor waters. Filled symbols represent data from station $45(\bullet)$, where diminished turbidity permitted a higher phytoplankton biomass to develop (see Fig. I for station locations). All vertical profiles extend to within approximately I meter of the bottom.

vious field seasons (Kuehl et al., 1986) indicated that there might be seasonal variability in the shoreward flux of offshore water. Based on seabed measurements of ${ }^{234} \mathrm{Th}$ (half life $24 \mathrm{~d}$ ) from the first three AmasSeds cruises, significant seasonal variation occurs in the inventory of this shortlived radionuclide (Fig. 4). The ${ }^{234} \mathrm{Th}$ inventories, generally, were highest during cruise I (falling river discharge) and lowest during cruise III (high river discharge). On times scales of months, the enhanced ${ }^{234} \mathrm{Th}$ inventories along the River-Mouth Transect and at the northernmost station (Cruise III) indicate areas where the onshore movement 


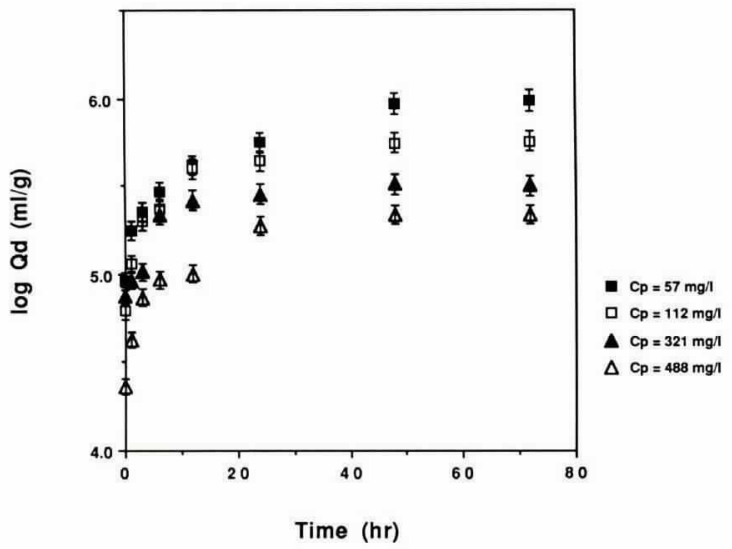

Fig. 3: ${ }^{234}$ Th distribution coefficients $\left(Q_{d}\right)$ plotted as a function of equilibration time after collection for various natural levels of suspended-solid concentration. $Q_{d}$ is equal to the ratio of particulate concentration to dissolved concentration. The initial non-equilibrium $Q_{d}$ values were observed because particle residence times on the Amazon shelf are short relative to characteristic sorption times for thorium. Equilibrium $Q_{d}$ values are inversely proportional to particle concentration $\left(C_{p}\right)$. The several day time period required to attain equilibrium between dissolved and particulate phases verifies the results of previous laboratory experiments (McKee et al., 1986).

... plumes of

freshened water exit

the Amazon shelf from

different areas ... or

the degree of water-

sediment interaction

varies on a time scale

of weeks. vide a direct estimate of the amount of sediment in contact with overlying waters and of the time the sediment has been stored in the system prior to losing Ra.

The ${ }^{228} \mathrm{Ra} /{ }^{226} \mathrm{Ra}$ signature of Amazon estuarine waters may be traced hundreds of kilometers into the Atlantic Ocean (Moore et al., 1986). Key et al. (1985) reported that desorption from Amazon River sediments increased the dissolved flux of ${ }^{226} \mathrm{Ra}$ and ${ }^{228} \mathrm{Ra}$ to the ocean five fold. In addition, Amazon shelf sediments were found to contribute significant amounts of both isotopes to the river/ ocean mixing zone. The influence of the Amazon upon the open Atlantic was unambiguous in July and September 1989. Salinities 500 to $1700 \mathrm{~km}$ from the river mouth ranged from 30.5 to 34.5 per mil (Fig. 5). These waters were enriched in ${ }^{228} \mathrm{Ra}$, but the correlation with salinity was weak. This implies either that plumes of freshened water exit the Amazon shelf from different areas where ${ }^{228} \mathrm{Ra}$ /salinity ratios vary, or that the degree of water-sediment interaction varies on a time scale of weeks.

The measurement and presence of short-lived ${ }^{224} \mathrm{Ra}$ allows an estimate of the time elapsed since

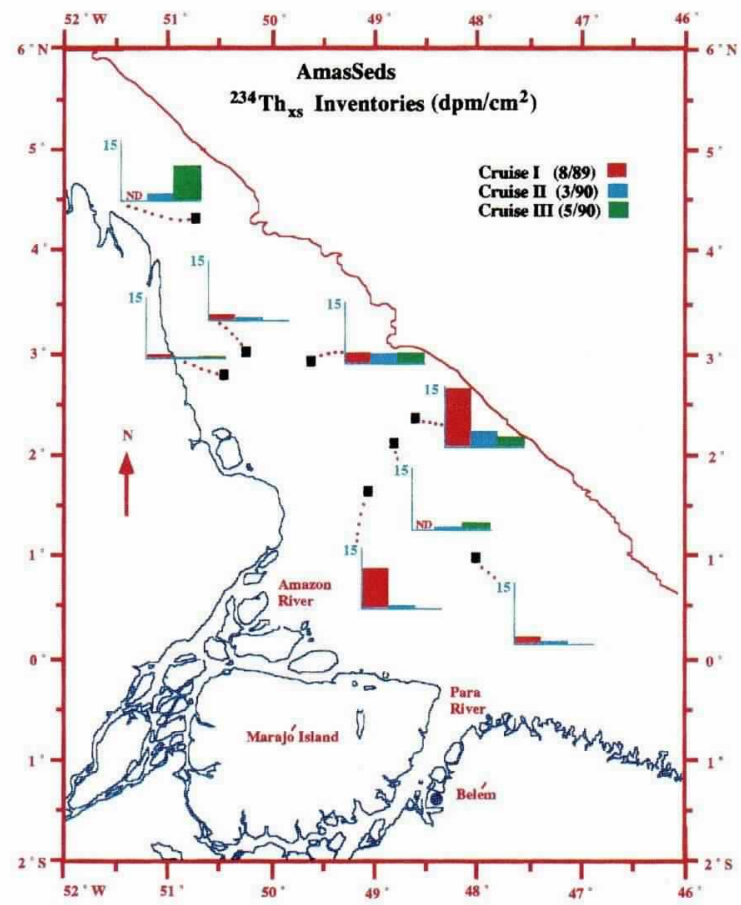

Fig. 4: Distribution of excess ${ }^{234}$ Th seabed inventories collected during AmasSeds cruises I, II, and III. The data indicate substantial seasonal variability in offshore/onshore exchange processes, scavenging, and particle deposition. The inventories are highest along the River-Mouth Transect and at the northernmost station indicating areas where the exchange, scavenging, and depositional processes are most active. The height of the y-axis for each of the graphs corresponds to an inventory

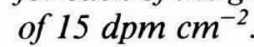




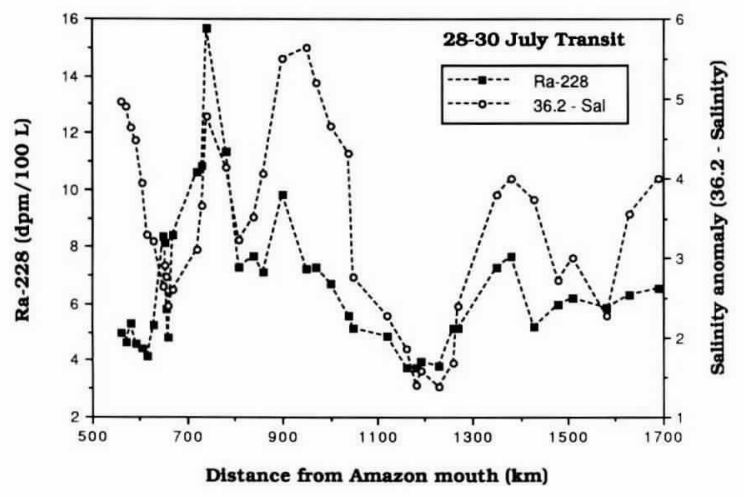

Fig. 5: ${ }^{228}$ Ra activities as a function of distance from the Amazon River mouth. Plumes of freshened surface waters were sampled during 28-30 July 1989. The activity of ${ }^{228} \mathrm{Ra}$ in these plumes varied from 5 to $16 \mathrm{dpm}(100 \mathrm{l})^{-1}$. The preliminary interpretation is that the ${ }^{228} \mathrm{Ra} /$ salinity ratio in the Amazon River/ocean mixing zone varies on a time scale of weeks due to differences in the intensity of seawater/sediment interaction.

the water left the Amazon shelf over a time scale of about five half lives (two to three weeks). AmasSeds is the first project to use this short-lived radium isotope to evaluate transport rates in a major dispersal system. In July and September 1989, salinities of 31 to 32 per mil and excess ${ }^{224} \mathrm{Ra}$ activities of 15 to $20 \mathrm{dpm}(100 \mathrm{l})^{-1}$ were measured in the region of the North Brazil Current retroflection $\left(8^{\circ} \mathrm{N}, 380 \mathrm{~km}\right.$ offshore). This implies that waters in the core of the retroflection were $<5$ days removed from the ${ }^{224} \mathrm{Ra}$ source (i.e., the deltaic muds on the Amazon shelf). To move the waters this distance requires a sustained current of $>80 \mathrm{~cm} / \mathrm{sec}$. This observation agrees with the drogue tracks during the August 1989 hydrography leg (Limeburner et al., 1990).

Another tracer used to evaluate circulation, water mass origin, and river discharge variability is the oxygen isotopic composition of the water. These isotopic data, which are reported relative to the reference material SMOW (Standard Mean Ocean Water), have been used to delineate three different water masses on the shelf: river water, open-ocean surface water, and open-ocean intermediate water (Fig. 6A). The distribution patterns of $\delta^{18} \mathrm{O}_{\text {smow }}$ are fairly similar to those of surface salinity, however, the ratio of $\delta^{18} \mathrm{O}_{\text {smow }}$ to salinity changes seasonally (Fig. 6B). The $\delta^{18} \mathrm{O}$ composition of the 0 per mil salinity end member is more positive during the rising discharge period than during the falling or peak discharge period. This is most likely related to the amount of water recycling (evaporation/precipitation) in different parts of the Amazon basin. Martinelli and Richey (1990) observed that there are two sources of water in the Amazon basin, a heavier water evaporated from the Atlantic Ocean that is recycled in the rainforest and a lighter water supplied from the Andes.

\section{Future Work}

The time series of geochemical measurements will be complete following AmasSeds Cruise IV, (the November 1991 cruise during the period of minimum discharge from the river). When the geochemical measurements from these studies are finished, the data will be compared to the obser-
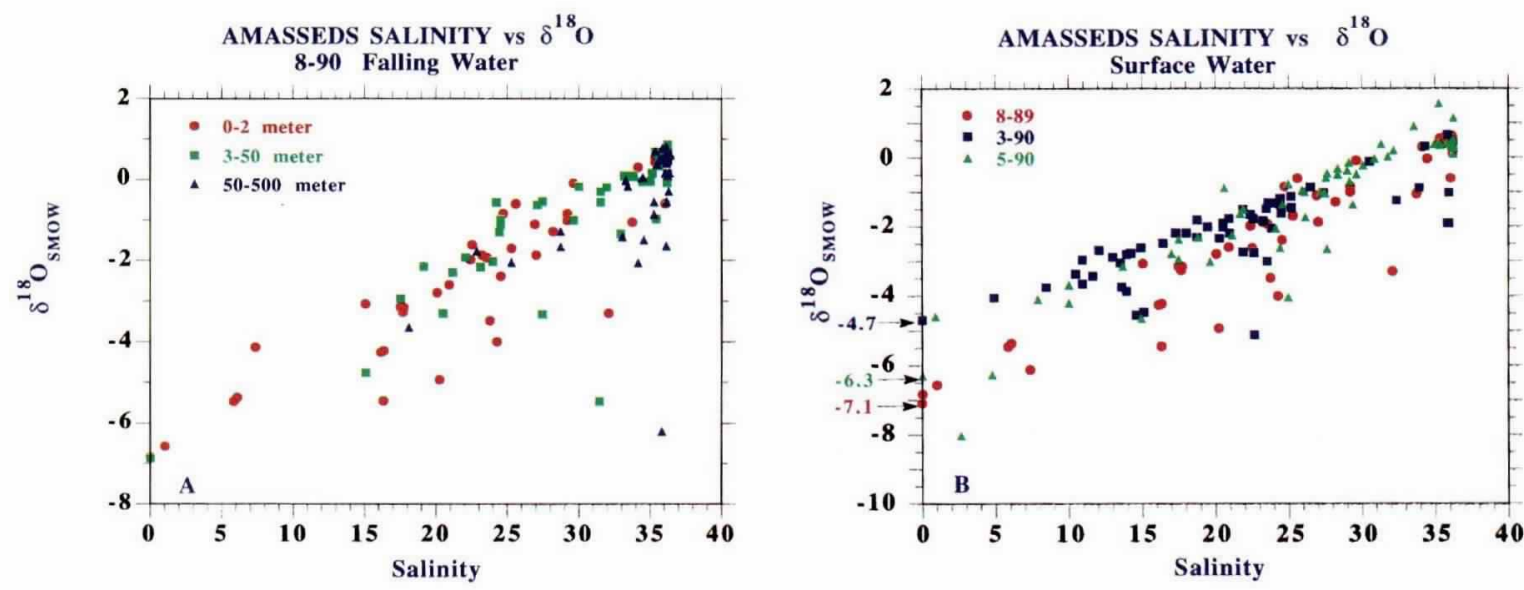

Fig. 6: A. The relationship between salinity and oxygen isotopic composition for surface, intermediate, and deep Amazon coastal waters from the August 1989 falling river discharge cruise. The salinityoxygen relationship is non-linear suggesting that on the shelf there is mixing between three different water masses: riverine water, open-ocean surface water, and open-ocean intermediate water. B. The relationship between salinity and oxygen isotopic composition for shelf surface waters (0 to 3 meters) from the rising, falling, and peak river discharge cruises. The oxygen isotopic composition of the riverine end member (noted on the y-axis) changes seasonally. The most positive oxygen isotopic end member was observed during the falling river discharge cruise. Variation of the riverine isotopic end member is related to atmospheric transport and recycling of water vapor in the Amazon Basin. 
vations of other AmasSeds investigators who are examining seabed geochemistry, sediment transport, frontal zone dynamics, and sedimentation. Models developed from the AmasSeds physical oceanographic data will be modified to evaluate estuarine chemical dynamics such as nutrient uptake and particle scavenging.

\section{Acknowledgements}

We would like to thank the crew of the $R / V$ COLUMBUS ISELIN and our Brazilian colleagues for their assistance in sample collection. We are grateful for the long hours put in by our graduate students and sea-going staff, who include Heather Astwood, Greg Booth, JoLynn Carroll, Bernie Genna, Dennis Guffey, Stephen Harden, Linda Herlihy, Holly Kelly, Robin Pope, Jim Rich, Heinz Seltmann, Donnie Smoak, and Pete Swarzenski. Our research was supported by grants from the National Science Foundation, Chemical Oceanography Program.

\section{References}

Boyle, E.A., J.M. Edmond and E.R. Sholkovitz, 1977: On the mechanism of iron removal in estuaries. Geochim. Cosmochim. Acta, 41, 1313-1324.

Brzezinski, M.A. and D.M. Nelson, 1989: Seasonal changes in the silicon cycle with a Gulf Stream warm-core ring. Deep-Sea Res., 36, 1009-1030.

Curtin, T.B. and R.V. Legeckis, 1986: Physical observations in the plume region of the Amazon River during peak discharge-I. Surface variability. Cont. Shelf Res., 6, 3152.

DeMaster, D.J., G.B. Knapp and C.A. Nittrouer, 1983: Biological uptake and accumulation of silica on the Amazon continental shelf. Geochim. Cosmochim. Acta, 47, 1713-1723.

__ S.A. Kuehl and C.A. Nittrouer, 1986: Effects of suspended sediments on geochemical processes near the mouth of the Amazon River: examination of biogenic silica uptake and the fate of particle-reactive elements. Cont. Shelf Res., 6. 107-125.

Edmond, J.M., E.A. Boyle, B. Grant and R.F. Stallard, 1981: The chemical mass balance in the Amazon plume: the nutrients. Deep-Sea Res., 28, 1339-1374.
Fox, L.E., S.L. Sager and S.C. Wofsy, 1986: The chemical control of soluble phosphorus in the Amazon estuary. Geochim. Cosmochim. Acta, 50, 783-794.

Elsinger, R.J. and W.S. Moore, 1983: ${ }^{224} \mathrm{Ra},{ }^{228} \mathrm{Ra}$, and ${ }^{226} \mathrm{Ra}$ sources in Winyah Bay and Delaware Bay. Earth Planet. Sci. Lett., 64, 430-436.

Honeyman, B.D. and P.H. Santschi, 1989: A Brownian-pump model for oceanic trace metal scavenging: evidence from Th isotopes. Jour. Mar. Res., 47, 951-992.

Key, R.M., R.F. Stallard, W.S. Moore and J.L. Sarmiento, 1985: Distribution of ${ }^{226} \mathrm{Ra}$ and ${ }^{228} \mathrm{Ra}$ in the Amazon River estuary. Jour. Geophys. Res., 90, 6995-7005.

Kuehl, S.A., D.J. DeMaster and C.A. Nittrouer, 1986: Nature of sediment accumulation on the Amazon continental shelf. Cont. Shelf Res., 6, 209-226.

Limeburner, R., R.C. Beardsley and R.V. Legeckis, 1990: Water properties and Lagrangian circulation over the North Brazilian shelf, EOS, 71, 1365.

Livingstone, D.A., 1963: Chemical composition of rivers and lakes. U.S. Geological Survey, Prof. Paper, 440-G, 63 pp.

Martinelli, L.A. and J.E. Richey, 1990: Isotopic signature of precipitation and runoff at subbasin scales in the Amazon. EOS, 71, 1244.

McKee, B.A., D.J. DeMaster and C.A. Nittrouer, 1986: Temporal variability in the partitioning of thorium between dissolved and particulate phases on the Amazon shelf: implications for the scavenging of particle-reactive species. Cont. Shelf Res., 6, 87-106.

Milliman, J.D. and E.A. Boyle, 1975: Biological uptake of dissolved silica in the Amazon River estuary. Science, 189, 995-997.

Moore, W.S., 1981: Radium isotopes in Chesapeake Bay. Estuar. Coast. Shelf Sci., 12, 713-723.

, J.L. Sarmiento and R.M. Key, 1986: Tracing the Amazon component of surface Atlantic water using ${ }^{228} \mathrm{Ra}$, salinity, and silica. Jour. Geophys. Res., 91, 25742580 .

Nelson, D.M. and J.J. Goering, 1977: Near-surface silica dissolution in the upwelling region off northwest Africa. Deep-Sea Res., 24, 65-73.

J.J. Goering and D.W. Boisseau, 1981: Consumption and regeneration of silicic acid in three coastal upwelling systems. In: Coastal Upwelling. F.A. Richards, ed., American Geophysical Union, 242-256.

Sholkovitz, E.R., E.A. Boyle and N.B. Price, 1978: The removal of dissolved humic acids and iron during estuarine mixing. Earth Planet. Sci. Lett., 40, 130-136. 